\title{
PENINGKATAN PEREKONOMIAN KELOMPOK UKM KUE BASAH DESA SAMBIREJO MELALUI PEMANFATAAN ENERGI ALTERNATIF
}

\author{
Margianto', Sugiono ${ }^{2}$ \\ ${ }^{1}$ Fakultas Teknik Universitas Islam Malang \\ email : margianto74@yahoo.com \\ 2 Fakultas Teknik Universitas Islam Malang \\ email : sugiono.unisma@gmail.com
}

\begin{abstract}
Sambirejo village have interested potensial among other villages around. The potensial is there are some group of wet cake small businessman. There are 14 small businessman that have many worker among their family.Many years ago the small businessman used LPG (Liquid Petrolium Gas) or woods as source of fire energy to run their working. So that there some negative effect like dangerous of blowing LPG or the emptiness of wood supply. Also they used manual tools to process the wet cake that make unefficently bussiness. The small businessman have many cows and garden that can be used to make biogas installation with use cows manure.Through this campus activity, the businessman at last have biogas installation as fire alternative energy and mechanical tools (mixer cake) to process their working.Output of the program are, the small businessman have ability to efficiently and faster the production process
\end{abstract}

Keywords : wet cake, Sambirejo village, Biogas, cow, LPG

\section{PENDAHULUAN}

Desa Sambirejo merupakan salah satu desa yang masuk Kab. Ngawi, berada di bagian barat provinsi Jawa Timur di kaki pegunungan. Tinggi dari atas permukaan laut kira-kira $471 \mathrm{~m}$ dan secara geografis terletak di posisi

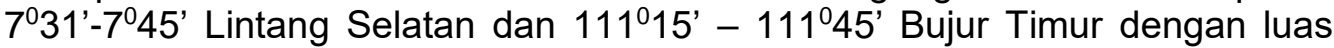
wilayah : $150.864 \mathrm{Ha}$

Penghasilan utama dari desa adalah padi, ketela pohon, ubi jalar serta tanaman pertanian lain dengan profesi utama penduduknya adalah petani. Selain itu jenis pekerjaan lain yang dilakukan adalah : pengusaha kue, pedagang, pemilik toko, warung makan, guru, PNS, pekerja migran (TKI/TKW), buruh tani, ternak kambing dan ternak sapi.

2Desa Sambirejo memiliki potensi yang menarik jika dibadingkan dengan desa sekitarnya yaitu terdapatnya kelompok pengusaha aneka kue kue basah baik dalam bentuk kue basah. Jumlah UMKM kue di desa Sambirejo mencapai 14 pengusaha yang masing-masing masih mempekerjakan beberapa orang karyawan yang berasal dari sanak famili maupun tetangga sekitar rumah.

Para pengusaha menjual kuenya dengan harga rata-rata berkisar Rp. 500 sampai Rp. 1000 per buah. Jenis kue yang diproduksi : onde-onde, klepon, 
kue misis, ager-ager, wingko, roti kukus, putu ayu, bakpao, donat, molen, pastel, lumpia, dadar gulung, martabak telor, lapis, mutioro, kue stik, pia, terang bulan, kue boneka. Kapasitas produksi setiap pengusaha per hari ratarata mencapai : 1500 buah Dengan omset setiap hari rata-rata mencapai : Rp. 1500.000 s/d Rp. 2.000 .000

Sistem manajemen penjualan dilakukan dengan : (1) Barang dagangan diambil oleh para tengkulak. (2) Barang dagangan dibawa ke pasar kemudian dibeli secara grosir oleh para tengkulak. (3) Barang dagangan dijual dengan sistem pesanan.

Dalam pembelian bahan baku berupa tepung terigu, tepung beras, gula, telor dan lain-lain dilakukan secara berkelompok agar mendapat harga murah. Tetapi dalam sistem penjualan dilakukan dengan cara sendiri-sendiri. Setiap hari produksi makanan kecil para pengusaha di jual ke pasar-pasar desa dan toko di sekitar kota Ngawi hingga kota Sragen dan kota Madiun. Dalam memproduksi makanan kecil, para pengusaha terbiasa menggunakan LPG kapasitas $12 \mathrm{~kg}$ maupun $3 \mathrm{~kg}$ atau kayu sebagai bahan bakar. Bahan bakar kayu diperoleh dari kebun atau membeli kayu dari penjual kayu keliling yang mendapatkan ranting-ranting kayu dari hutan sekitar desa.

\section{METODE}

Metode pendekatan dalam kegiatan IbM ini adalah dengan action research dimana akan dilakukan proses penerapan teknologi tepat guna dan pendampingan produksi untuk membantu kelompok UKM Kue Basah. Solusi yang ditawarkan berupa upaya peningkatan efisiensi produksi, kebersihan dan kesehatan proses produksi kue basah. Bentuk upaya tersebut dapat diuraikan sebagai berikut :

- Permasalahan energi yaitu efisiensi penggunaan LPG dan kayu hutan sebagai bahan bakar dapat diatasi dengan membangun instalasi energi alternatif biogas kapasitas $4 \mathrm{~m}^{3}$ sebanyak 2 buah sebagai penampung kotoran sapi untuk dijadikan bahan bakar sekaligus sebagai sumber listrik.

- Proses pengadukan adonan kue yang masih manual dapat diatasi dengan memberikan mesin mixer berbagai adonan kue sebanyak 2 buah.

- Pemberian pelatihan dan pendidikan kebersihan dan kesehatan dalam memproduksi Kue Basah selama kegiatan berlangsung. Prosedur kerja yang akan diterapkan berupa:

- Sosialisasi kegiatan ke mitra UKM,

- Pembuatan mesin mixer kue dan pembuatan kompor biogas

- pembangunan instalasi biogas

- pengujian mixer yang dilanjutkan dengan pemberian mesin mixer beserta pemberian pelatihan pengoperasian ke UKM Mitra.

- pengujian instalasi biogas dilanjutkan dengan penyerahan instalasi biogas beserta pemberian pelatihan perawatan dan pengoperasiannya ke UKM Mitra. 
- Melakukan pendampingan ke mitra dalam penggunaan peralatan hasil kegiatan.

- Pelaksanaan pendidikan dan pelatihan kebersihan dan kesehatan proses produksi.

- Evaluasi kegiatan yang dilakukan antara tim pengabdi bersama Mitra UKM.

Rencananya, mesin mixer dan kompor biogas akan dibuat di bengkel kerja di Malang dan setelah melalui proses uji coba, alat -alat tersebut akan dibawa ke lokasi kegiatan di desa Sambirejo. Sesampai di lokasi kegiatan, akan dimulai pembangunan instalasi biogas. Selama proses tersebut akan dilakukan pelatihan dan pendampingan penggunaan mesin mixer kue sampai anggota kelompok UKM memahami aspek pengoperasian dan perawatannya. Selanjutnya dilakukan proses penyerahan mixer kue ke UKM Mitra. Pelatihan dan pendidikan kebersihan dan kesehatan kerja mulai dilakukan dengan dukungan dari partisipasi Mitra UKM. Pendampingan dilakukan terus menerus selama kegiatan berlangsung baik terhadap aplikasi mixer kue maupun aplikasi tindakan kebersihan dan kesehatan kerja.

Jika instalasi biogas telah selesai, maka akan dilakukan proses uji coba hingga diperoleh api yang biru. Kemudian dilakukan pelatihan ke UKM Mitra tentang pengoperasian dan perawatan instalasi yang dilanjutkan dengan pendampingannya hingga UKM mitra paham aspek pengperasian dan perawatannya.

\section{HASIL DAN PEMBAHASAN}

Hasil yang telah dicapai berupa :

1. Terlaksananya pelatihan /penyuluhan instalasi biogas. Kegiatan ini diselenggarakan di rumah ketua UKM kue basah desa Sambirejo dan diikuti oleh anggota UKM kue basah. Setelah mengikuti kegiatan peserta dapat memahami aspek - aspek pemanfaatan biogas dalam usaha kue basah terutama sebagai bahan bakar alternative selain LPG dan kayu bakar

2. Terbangunnya instalasi biogas $10 \mathrm{~m}^{3}$ atau $5 \times 2 \mathrm{~m}^{3}$ bertempat dihalaman belakang rumah ketua UKM kue basah yang sekaligus berfungsi sebagai tempat berkumpulnya para pengusaha tersebut.

3. Kompor biogas dibuat dan diserahkan ke mitra beserta penyuluhan cara pemakaiannya. Selain itu pengusaha juga mendapat penjelasan tentang perawatan kompor biogas dan cara kerja yang memenuhi standar keselamatan pemakaian.

4. Mesin mixer $8 \mathrm{~kg}$ telah diserahkan ke mitra beserta penyuluhan cara pemakaian dan perawatan. Setelah dicoba dilokasi mitra maka diperoleh hasil berupa penghematan waktu proses pengerjaan kue serta hasil kue menjadi lebih banyak jika dibanding dengan pemakaian tenaga manual.

5. Mitra telah mengetahui dan memahami cara pemanfaatan pupuk cair dan padat sisa luaran biogas kotoran ternak. Sebelum ada kegiatam IbM, 
masyarakat terbiasa menumpuk kotoran sapi untuk nantinya dimanfaatkan sebagai pupuk kandang tanpa ada proses apapun sebelumnya. Namun setelah mengetahui adanya pupuk cair dan padat dari hasil fermentasi kotoran sapi yang dimasukkan ke dalam instalasi biogas maka para UKM kue memahami cara memperoleh nilai lebih dari kotoran sapi tersebut.

\section{KESIMPULAN}

Kesimpulan yang bisa ditarik dari hasil kegiatan adalah sebagai berikut :

1. Penggunaan Biogas dapat mengurangi penggunaan LPG dan kayu dalam memproduksi kue basah. Pemakaian LPG turun menjadi 10 hari sekali, biasanya setiap hari butuh $3 \mathrm{~kg}$ LPG dan kayu.

2. Penggunaan mesin mixer $8 \mathrm{~kg}$ hasil kegiatan $\mathrm{lbM}$ dapat mempercepat proses produksi hingga 4 kali lipat.

3. Sisa instalasi biogas berupa limbah cair dan padat dapat dipakai sebagai pupuk organik sehingga mengurangi pemakaian pupuk non organik.

\section{REFERENSI}

[1] Krishnan, R, 2001, edisi 3, Electric Motor Drives Modelling, analysis and control, Prentice Hall International inc., Virginia. USA.

[2] Simamora, Suhut, 2006, edisi 1, Membuat biogas pengganti bahan bakar minyak dan gas dari kotoran ternak, PT Agromedia Pustaka, Depok

[3] Wahyuni, Sri, 2008, edisi 1, Biogas, Penebar Swadaya, Jakarta 